\title{
Linking bird species traits to vegetation characteristics in a future urban development zone: implications for urban planning
}

\author{
Karen Ikin • Emma Knight • David B. Lindenmayer • \\ Joern Fischer • Adrian D. Manning
}

(C) Springer Science+Business Media, LLC 2012

\begin{abstract}
Identifying the relationships between species traits and patch-scale vegetation characteristics in areas designated for urban development can improve our understanding of how animal communities may change with urbanization. We explored the implications of this premise to the urban planning process in a mixed-use landscape in Canberra (Australia), prior to its development into new suburbs. We used RLQ analysis to relate bird foraging, nesting and body size traits to patch-scale vegetation characteristics. Relationships between species traits and vegetation characteristics within the development zone suggest that species that forage and nest on the ground and in the understory strata, and smaller-bodied species will be most negatively affected by urbanization. Identifying the relationships between species traits and vegetation characteristics may be used by urban planners to (i) identify potentially critical habitat and species at risk from development, (ii) inform the choice of impact mitigation measures, and/or (iii) distinguish between high and low mitigation
\end{abstract}

K. Ikin $(\bowtie) \cdot$ D. B. Lindenmayer $\cdot$ J. Fischer $\cdot$ A. D. Manning

The Fenner School of Environment and Society, The Australian National University, Canberra, ACT 0200, Australia

e-mail: karen.ikin@anu.edu.au

D. B. Lindenmayer

e-mail: david.lindenmayer@anu.edu.au

J. Fischer

e-mail: joern.fischer@uni.leuphana.de

A. D. Manning

e-mail: adrian.manning@anu.edu.au

E. Knight

Centre for Mathematics and its Applications, The Australian National University,

Canberra, ACT 0200, Australia

e-mail: emma.knight@anu.edu.au

J. Fischer

Institute of Ecology, Leuphana University Lueneburg, 21335 Lueneburg, Germany 
measures. Analyses conducted early in the planning process can then be used to allocate proposed land uses in an ecologically sensitive way, and to plan appropriate mitigation measures.

Keywords Community composition $\cdot$ Conservation planning $\cdot$ Impact mitigation $\cdot$ RLQ analysis $\cdot$ Southeastern Australia $\cdot$ Urbanization

\section{Introduction}

A significant challenge for conservationists, urban policy makers, planners and developers is to understand how animal communities may change with future urbanization (Soule 1991; McDonald 2008; Gordon et al. 2009). Globally, more than $50 \%$ of all humans live in urban areas and this proportion is growing rapidly (McDonald 2008). The associated increase in land conversion for urbanization represents a major form of landscape change (Foley et al. 2005). Understanding how this form of disturbance may affect animal communities before urbanization occurs may lead to more informed management of negative development impacts, such as changes to the location, type and configuration of proposed development projects.

Identifying the current relationships between species traits and vegetation characteristics may improve our understanding of the effects of urbanization by distinguishing the species most at risk from landscape change (Hausner et al. 2003; de Voogd and Cleary 2007; Rachello-Dolmen and Cleary 2007; Webb et al. 2010). Species' ecological or behavioral traits shape community composition because the probability of occurrence of an individual species in a given location will often be driven by the match between vegetation characteristics and the species' evolved biological traits (Cleary et al. 2007; Hirzel and Le Lay 2008; Lacourse 2009). Species traits provide a mechanistic link between the functional diversity of an animal community and landscape characteristics (Kennedy et al. 2010; Williams et al. 2010). These traits may therefore give more insight into community responses to disturbance than conventional species richness metrics (Hausner et al. 2003). Declining species may share ecological or behavioral traits, and so the identification of which traits make a species sensitive to landscape change may be used to target groups of species for specific management actions (Barbaro and van Halder 2009).

One method of directly relating species traits to vegetation characteristics is RLQ analysis (Doledec et al. 1996). This method links species traits to vegetation characteristics by the simultaneous ordination of the vegetation characteristics at each site $(\mathrm{R})$, the species present $(\mathrm{L})$, and their life-history traits $(\mathrm{Q})$ and it has the advantage that multiple life-history traits can be assigned to each species. RLQ analysis has been applied to a wide range of taxa, including bat and fish assemblages in North America (Duchamp and Swihart 2008; Brind'Amour et al. 2011), ground beetles in the United Kingdom (Ribera et al. 2001), birds, insects and spiders in Europe (Hausner et al. 2003; Le Viol et al. 2008; Barbaro and van Halder 2009; Lizée et al. 2011), bird assemblages in Africa (Seymour and Dean 2010), and butterflies and coral in southeast Asia (Rachello-Dolmen and Cleary 2007; Cleary et al. 2009). It also has been applied to a range of human-disturbed environments, including abandoned fields (Bernhardt-Romermann et al. 2008), logged forest (Cleary et al. 2007), and urban areas (Threlfall et al. 2011). By providing an overview of current species' responses to particular land uses and vegetation characteristics (based on known species traits), RLQ analysis can improve understanding of which species may be affected by future landscape change. Thus, RLQ analysis has the potential to remove much uncertainty regarding animal community responses to urbanization before detailed planning begins (Williams et al. 2010). 
We present a case study from southeast Australia of a mixed-use landscape, prior to its planned urban development. Specifically, we asked: Can investigating the current relationships between bird life-history traits and patch-scale vegetation characteristics be used to inform which bird species may be most at risk from future urbanization because of landscape change? We used RLQ analysis to relate bird species traits to vegetation characteristics, and used the results of this analysis to evaluate the effects of planned urban development. Previous studies worldwide have reported relationships between vegetation structures and birds with particular traits (e.g. O'Connell et al. 2000; Heikkinen et al. 2004; Loyn and Kennedy 2009; deMars et al. 2010), and we expected our RLQ analysis to confirm these relationships. However, our approach was innovative because it allowed us to understand which groups with similar life-history traits may be affected by future urbanization. We show that RLQ analysis promises to be a useful tool to assist urban planning, which could be integrated within existing environmental assessment procedures for the identification of high-priority mitigation measures to be included in management plans (Webb et al. 2010). Our study findings also have wider relevance to urban planning and animal conservation elsewhere in the world where urban expansion is also prevalent but methods facilitating early conservation planning are not well developed (Ignatieva 2010).

\section{Materials and methods}

\section{Study area and site selection}

Our study was located within the lower Molonglo Valley in Canberra, the Australian Capital Territory (ACT), Australia (Fig. 1; also see Stagoll et al. 2010). The Molonglo Valley, which borders the Molonglo River, lies $7.5 \mathrm{~km}$ west of the Canberra urban centre, covers an area of more than 6000 ha, and is surrounded by established suburbs and agricultural land. The next centre of major suburban development in the Canberra region will cover approximately one third of this area (ACTPLA 2006). The process of urbanization began with the release of land in the southeast of the valley in 2009. Thirteen suburbs are planned, and initial block sizes range from $330 \mathrm{~m}^{2}$ to $980 \mathrm{~m}^{2}$. Current estimates predict that up to 55000 people will live in the Molonglo Valley by 2030 (LDA 2010).

At the time of this study (November 2008), the Molonglo Valley was a mixed-use landscape, and the main categories of land zoning were "rural land" (mostly livestock grazing), "river corridor" (riparian areas along the Molonglo River) and "plantation forestry" (dominated by radiata pine, Pinus radiata). Land within the plantation forestry areas has not been replanted since a wildfire burnt through the valley in 2003, but P. radiata and Acacia spp. regrowth has occurred.

We used current ACT Government vegetation maps and aerial photographs to identify rural, riparian and plantation land uses within the Molonglo Valley (Fig. 1a). We then further divided these categories into treeless and treed areas (with Eucalyptus spp. or Casuarina spp. tree cover, or P. radiata and Acacia spp. regrowth). This gave five vegetation classes: (1) rural treed, (2) rural treeless, (3) riparian treed, (4) riparian treeless and (5) plantation treed. We mapped these vegetation classes in a GIS and quantified their area within the Molonglo Valley (Table 1). A sixth vegetation class, commercial vineyard, also occurs in the study area, but we did not include commercial vineyard in our study because: (1) the area of vineyards is small and we were primarily interested in the main combinations of land use and tree cover occurring within the Molonglo Valley, and (2) vineyards are not targeted for urban development. 
Fig. 1 Map of the Molonglo Valley study area, located in Canberra, Australian Capital Territory, Australia. Six vegetation classes were distinguished and 75 sampling sites were selected (a). A site consisted of two adjoining 0.8 ha circles, with one survey point at the centre of each circle (b). The Molonglo Valley development zone was located in the southwest of the study area. This zone included future urban land and river corridor areas bordered by urban land (c)

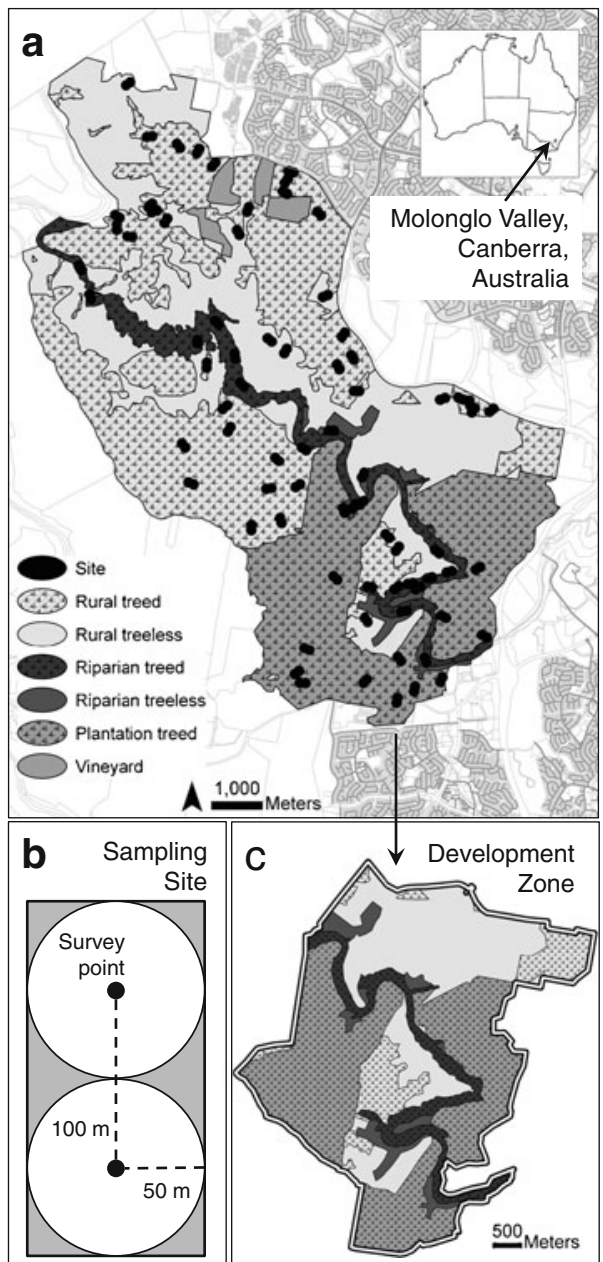

We selected 75 sites across the Molonglo Valley (see Stagoll et al. 2010 for detailed site selection methods). A site consisted of two adjoining $50 \mathrm{~m}$ radii $(0.8 \mathrm{ha})$ circles, with one survey point at the centre of each circle (Fig. 1b; Manning et al. 2011). We determined the number and placement of sites using stratified random sampling, so that sites were spread across the five vegetation classes (Table 1).

Future development zone

To quantify the extent that each of the five vegetation classes will be affected by the planned development, we used a GIS-based approach to map the Molonglo Valley development zone (Fig. 1c). This zone included future urban land (residential, commercial, community facility, parks and recreation, and transport and services land designations). We also included river corridor areas bordered by urban land in the development zone because these areas will be part of future public urban open space. We then calculated the area and proportion of each vegetation class falling within the development zone (Table 1). We assumed that all land 
Table 1 Summary (site number, total area, development area and proportion) of the six vegetation classes present in the Molonglo Valley, Canberra, Australia

\begin{tabular}{llllll}
\hline Vegetation class & Abbreviation & No. sites & $\begin{array}{l}\text { Area within } \\
\text { Molonglo } \\
\text { Valley (ha) }\end{array}$ & $\begin{array}{l}\text { Area within } \\
\text { development } \\
\text { zone (ha) }\end{array}$ & $\begin{array}{l}\text { Proportion within } \\
\text { development zone (\%) }\end{array}$ \\
\hline Rural treed & Ru. tr & 35 & 2546 & 219 & 8.6 \\
Rural treeless & Ru. tss & 7 & 1990 & 611 & 30.7 \\
Riparian treed & Ri. tr & 17 & 465 & 195 & 41.9 \\
Riparian treeless & Ri. tss & 3 & 110 & 101 & 91.8 \\
Plantation treed & P. tr & 13 & 1582 & 936 & 59.2 \\
Vineyard & - & 0 & 124 & 0 & 0 \\
Total & & 75 & 6818 & 2062 & 30.2 \\
\hline
\end{tabular}

The vegetation classes were distinguished by dividing rural, riparian and plantation land uses into treeless and treed areas (with Eucalyptus spp. and Casuarina cunninghamiana tree cover or Pinus radiata and Acacia spp. regrowth). Commercial vineyard was identified but not sampled. The development zone included future urban land and riparian areas bordered by urban land. The proportion of a vegetation class within the development zone was calculated as the proportion of the total area of that vegetation class that lies in the development zone.

within the development zone would be subject to substantial future modification, for example tree clearing, intensive landscaping, or fire management.

\section{Bird surveys and species traits}

We surveyed birds using fixed-radius point counts (Sutherland et al. 2004), at each of the two survey points at each site (following Manning et al. 2011). We recorded the presence of all bird species seen or heard within a $50 \mathrm{~m}$ radius during a $10 \mathrm{~min}$ timeframe. We surveyed each site twice during the field season (once by each of two observers on separate days) resulting in a total of $40 \mathrm{~min}$ of survey time per site. We reversed the order that sites were surveyed between observers. To minimize possible bias caused by weather, we did not conduct surveys during periods of rain or high wind. We conducted all surveys between dawn and 10 am during spring 2008. This period coincided with the peak breeding season in the ACT, when most birds, including summer migrants, establish breeding territories and exhibit strong site fidelity (Montague-Drake et al. 2009).

We assigned species to one of four habitat-association groups, using a list developed by Birds Australia (Silcocks et al. 2005): (1) woodland species; (2) grassland species; (3) generalists (associated with both woodland and grassland habitats); and (4) waterbirds (Table 2). The resulting groups included some birds that are also often found in other vegetation, e.g. the woodland species group included some species found in forest vegetation, such as the eastern yellow robin and crimson rosella (see Table 2 for scientific names of birds), but for the purposes of this analysis we maintained the general grouping of Silcocks et al. (2005). We then assigned ecological (foraging and nesting) and biological (body size) traits to each species (Table 3; HANZAB 1990-2007; Hausner et al. 2003). These traits reflect the phenology and physical requirements of each species, and the majority of previous work on bird community composition has used at least one of these traits for guild classification (e.g. Mac Nally 1994; Soderstrom et al. 2001). These species traits also have particular relevance for conservation-risk birds in southeastern Australia, which may be loosely identified by their body size, and foraging or nesting requirements (including, but not restricted to, small-bodied species, ground-foraging insectivores and hollow nesters; 
Table 2 Complete list of observed bird species with assigned foraging, nesting and body size traits

\begin{tabular}{|c|c|c|c|c|c|}
\hline & \multirow[t]{2}{*}{ Common name } & \multirow[t]{2}{*}{ Scientific name } & \multicolumn{3}{|l|}{ Trait } \\
\hline & & & Foraging & Nesting & $\begin{array}{l}\text { Body } \\
\text { size }\end{array}$ \\
\hline \multirow[t]{41}{*}{ Woodland species } & Black-faced Cuckoo-shrike & Coracina novaehollandiae & Arb & Arb & Lge \\
\hline & Brown Thornbill & Acanthiza pusilla & Shb & Usty & VSml \\
\hline & Brown Treecreeper & Climacteris picumnus & Arb & Hol & Sml \\
\hline & Brown-headed Honeyeater & Melithreptus brevirostris & $\mathrm{NF}$ & Arb & VSml \\
\hline & Buff-rumped Thornbill & Acanthiza reguloides & Shb & Opp & VSml \\
\hline & Common Bronzewing & Phaps chalcoptera & Gran & Opp & Lge \\
\hline & Crimson Rosella & Platycercus elegans & Gran & Hol & Lge \\
\hline & Diamond Firetail & Stagonopleura guttata & Gran & Arb & VSml \\
\hline & Dollarbird & Eurystomus orientalis & Air & Hol & Lge \\
\hline & Double-barred Finch & Taeniopygia bichenovii & Gran & Usty & VSml \\
\hline & Dusky Woodswallow & Artamus cyanopterus & Air & Opp & Sml \\
\hline & Eastern Rosella & Platycercus eximius & Gran & Hol & Lge \\
\hline & Eastern Spinebill & Acanthorhynchus tenuirostris & NF & Arb & VSml \\
\hline & Eastern Yellow Robin & Eopsaltria australis & Grnd & Arb & VSml \\
\hline & European Goldfinch & Carduelis carduelis & Gran & Arb & VSml \\
\hline & Fan-tailed Cuckoo & Cacomantis flabelliformis & Grnd & Opp & Sml \\
\hline & Golden Whistler & Pachycephala pectoralis & Arb & Usty & Sml \\
\hline & Grey Fantail & Rhipidura albiscapa & Arb & Arb & VSml \\
\hline & Grey Shrike-thrush & Colluricincla harmonica & Arb & Opp & Int \\
\hline & Horsfield's Bronze-Cuckoo & Chrysococcyx basalis & Arb & Opp & Sml \\
\hline & Laughing Kookaburra & Dacelo novaeguineae & Carn & Hol & Lge \\
\hline & Leaden Flycatcher & Myiagra rubecula & Arb & Arb & VSml \\
\hline & Mistletoebird & Dicaeum hirundinaceum & $\mathrm{NF}$ & Arb & VSml \\
\hline & New Holland Honeyeater & Phylidonyris novaehollandiae & NF & Usty & Sml \\
\hline & Noisy Friarbird & Philemon corniculatus & NF & Arb & Lge \\
\hline & Noisy Miner & Manorina melanocephala & Arb & Opp & Int \\
\hline & Pallid Cuckoo & Cuculus pallidus & Arb & Opp & Int \\
\hline & Pied Currawong & Strepera graculina & Arb & Arb & Lge \\
\hline & Red Wattlebird & Anthochaera carunculata & NF & Arb & Lge \\
\hline & Red-browed Finch & Neochmia temporalis & Gran & Usty & VSml \\
\hline & Red-capped Robin & Petroica goodenovii & Grnd & Arb & VSml \\
\hline & Red-rumped Parrot & Psephotus haematonotus & Gran & Hol & Int \\
\hline & Rufous Whistler & Pachycephala rufiventris & Arb & Arb & Sml \\
\hline & Sacred Kingfisher & Todiramphus sanctus & Grnd & Hol & Sml \\
\hline & Shining Bronze-Cuckoo & Chrysococcyx lucidus & Arb & Opp & Sml \\
\hline & Silvereye & Zosterops lateralis & Shb & Arb & VSml \\
\hline & Southern Whiteface & Aphelocephala leucopsis & Grnd & Opp & VSml \\
\hline & Speckled Warbler & Chthonicola sagittata & Grnd & Grnd & VSml \\
\hline & Spotted Pardalote & Pardalotus punctatus & Arb & Hol & VSml \\
\hline & Striated Pardalote & Pardalotus striatus & Arb & Hol & VSml \\
\hline & Striated Thornbill & Acanthiza lineata & Arb & Arb & VSml \\
\hline
\end{tabular}


Table 2 (continued)

\begin{tabular}{|c|c|c|c|c|c|}
\hline & \multirow[t]{2}{*}{ Common name } & \multirow[t]{2}{*}{ Scientific name } & \multicolumn{3}{|l|}{ Trait } \\
\hline & & & Foraging & Nesting & $\begin{array}{l}\text { Body } \\
\text { size }\end{array}$ \\
\hline & Superb Fairy-wren & Malurus cyaneus & Shb & Usty & VSml \\
\hline & Superb Parrot & Polytelis swainsonii & Gran & Hol & Lge \\
\hline & Varied Sittella & Daphoenositta chrysoptera & Arb & Arb & VSml \\
\hline & Weebill & Smicrornis brevirostris & Arb & Arb & VSml \\
\hline & Western Gerygone & Gerygone fusca & Arb & Arb & VSml \\
\hline & White-browed Scrubwren & Sericornis frontalis & Shb & Usty & VSml \\
\hline & White-plumed Honeyeater & Lichenostomus penicillatus & $\mathrm{NF}$ & Arb & VSml \\
\hline & White-throated Gerygone & Gerygone albogularis & Arb & Arb & VSml \\
\hline & White-throated Treecreeper & Cormobates leucophaeus & Arb & Hol & Sml \\
\hline & White-winged Chough & Corcorax melanorhamphos & Grnd & Arb & Lge \\
\hline & White-winged Triller & Lalage sueurii & Arb & Arb & Sml \\
\hline & Yellow-faced Honeyeater & Lichenostomus chrysops & $\mathrm{NF}$ & Usty & VSml \\
\hline \multirow[t]{8}{*}{ Grassland species } & Australian Wood Duck & Chenonetta jubata & $\mathrm{Aqu}$ & Hol & VLge \\
\hline & Australasian Pipit & Anthus novaeseelandiae & Grnd & Grnd & Sml \\
\hline & Crested Pigeon & Ocyphaps lophotes & Gran & Opp & Lge \\
\hline & Eurasian Skylark & Alauda arvensis & Grnd & Grnd & Sml \\
\hline & Nankeen Kestrel & Falco cenchroides & Carn & Opp & Lge \\
\hline & Straw-necked Ibis & Threskiornis spinicollis & $\mathrm{Aqu}$ & Usty & VLge \\
\hline & White-faced Heron & Egretta novaehollandiae & $\mathrm{Aqu}$ & Arb & VLge \\
\hline & White-fronted Chat & Epthianura albifrons & Grnd & Usty & VSml \\
\hline \multirow[t]{20}{*}{ Generalist } & Australian Magpie & Cracticus tibicen & Grnd & Arb & Lge \\
\hline & Australian Raven & Corvus coronoides & Grnd & Arb & VLge \\
\hline & Brown Quail & Coturnix ypsilophora & Gran & Grnd & Lge \\
\hline & Brown Songlark & Cincloramphus cruralis & Grnd & Grnd & Int \\
\hline & Common Blackbird & Turdus merula & Grnd & Arb & Int \\
\hline & Common Myna & Sturnus tristis & Grnd & Hol & Sml \\
\hline & Common Starling & Sturnus vulgaris & Grnd & Opp & Int \\
\hline & Fairy Martin & Petrochelidon ariel & Air & Opp & VSml \\
\hline & Galah & Cacatua roseicapilla & Gran & Hol & Lge \\
\hline & House Sparrow & Passer domesticus & Gran & Opp & Sml \\
\hline & Little Eagle & Hieraaetus morphnoides & Carn & Arb & VLge \\
\hline & Magpie-lark & Grallina cyanoleuca & Grnd & Arb & Int \\
\hline & Rainbow Bee-eater & Merops ornatus & Air & Grnd & Sml \\
\hline & Rufous Songlark & Cincloramphus mathewsi & Grnd & Grnd & Sml \\
\hline & Stubble Quail & Coturnix pectoralis & Gran & Grnd & Lge \\
\hline & Sulphur-crested Cockatoo & Cacatua galerita & Gran & Hol & VLge \\
\hline & Tree Martin & Petrochelidon nigricans & Air & Hol & VSml \\
\hline & Welcome Swallow & Hirundo neoxena & Air & Opp & VSml \\
\hline & Willie Wagtail & Rhipidura leucophrys & Arb & Arb & Sml \\
\hline & Yellow-rumped Thornbill & Acanthiza chrysorrhoa & Grnd & Arb & VSml \\
\hline Waterbird & Dusky Moorhen & Gallinula tenebrosa & Aqu & Opp & VLge \\
\hline
\end{tabular}


Table 2 (continued)

\begin{tabular}{|c|c|c|c|c|}
\hline \multirow[t]{2}{*}{ Common name } & \multirow[t]{2}{*}{ Scientific name } & \multicolumn{3}{|l|}{ Trait } \\
\hline & & Foraging & Nesting & $\begin{array}{l}\text { Body } \\
\text { size }\end{array}$ \\
\hline Golden-headed Cisticola & Cisticola exilis & $\mathrm{Aqu}$ & Usty & VSml \\
\hline Grey Teal & Anas gracilis & Aqu & Hol & Lge \\
\hline Little Pied Cormorant & Phalacrocorax melanoleucos & Aqu & Arb & VLge \\
\hline Nankeen Night Heron & Nycticorax caledonicus & $\mathrm{Aqu}$ & Usty & VLge \\
\hline Pacific Black Duck & Anas superciliosa & $\mathrm{Aqu}$ & Opp & VLge \\
\hline
\end{tabular}

Species are grouped by habitat guilds (Silcocks et al. 2005) and nomenclature is taken from Christidis and Boles (2008). Foraging abbreviations: "Grnd" is ground insectivore, "Shb" is shrub insectivore, "Arb" is arboreal insectivore, "Air" is aerial insectivore, "Gran" is granivore, "NF" is nectar and fruit, "Carn" is carnivore, and "Aqu" is aquatic. Nesting abbreviations: "Grnd" is ground, "Usty" is understorey, "Arb" is arboreal, "Hol" is hollow, and "Opp" is opportunistic. Body size abbreviations: "VSml" is <20 g, "Sml" is 20$50 \mathrm{~g}$, "Int" is $50-100 \mathrm{~g}$, "Lge" is $100-500 \mathrm{~g}$, and "VLge" is $>500 \mathrm{~g}$.

Reid 1999; Ford et al. 2001; Barrett et al. 2007; Lindenmayer and Cunningham 2011). Detailed information on these traits was available for all of the species we recorded (HANZAB 1990-2007).

\section{Vegetation characteristics}

We quantitatively characterized vegetation within $50 \mathrm{~m}$ of each survey point and aggregated data to the site level. We recorded seven variables to reflect the patch-scale vegetation characteristics of each site: (1) dominant bark type; (2) tree stem density; (3) presence of tree hollows

Table 3 Ecological (foraging and nesting) and biological (body size) traits were recorded for each species and used in the RLQ analysis

\begin{tabular}{|c|c|c|}
\hline Species trait & Category & Abbreviation \\
\hline \multirow{8}{*}{$\begin{array}{l}\text { Dominant foraging diet and/ } \\
\text { or substrate }\end{array}$} & Ground insectivore & F:Grnd \\
\hline & Shrub insectivore & F:Shb \\
\hline & Arboreal insectivore & F:Arb \\
\hline & Aerial insectivore & F:Air \\
\hline & Granivore & $\mathrm{F}: G r a n$ \\
\hline & Nectar and fruit & $\mathrm{F}: \mathrm{NF}$ \\
\hline & Carnivore & F:Carn \\
\hline & Aquatic & $\mathrm{F}: \mathrm{Aqu}$ \\
\hline \multirow[t]{5}{*}{ Dominant nesting substrate } & Ground & $\mathrm{N}:$ Grnd \\
\hline & Understory & $\mathrm{N}:$ Usty \\
\hline & Arboreal & $\mathrm{N}: \mathrm{Arb}$ \\
\hline & Hollow & $\mathrm{N}: \mathrm{Hol}$ \\
\hline & Opportunistic & N:Opp \\
\hline \multirow[t]{5}{*}{ Body size } & Very small: $<20 \mathrm{~g}$ & S:VSml \\
\hline & Small: $20-50 \mathrm{~g}$ & $\mathrm{~S}: \mathrm{Sml}$ \\
\hline & Intermediate: $50-100 \mathrm{~g}$ & S:Int \\
\hline & Large: $100-500 \mathrm{~g}$ & S:Lge \\
\hline & Very large: $>500 \mathrm{~g}$ & S:VLge \\
\hline
\end{tabular}


(cavities); (4) presence of tree regeneration; (5) percent cover of shrubs; (6) presence of the exotic weed blackberry (Rubus fruticosus aggregate); and (7) percent cover of grass (Table 4). These variables have previously been found to be important for birds (e.g. Heikkinen et al. 2004; McElhinny et al. 2006; Montague-Drake et al. 2009; deMars et al. 2010).

Relationship between species traits and vegetation characteristics

We used RLQ analysis (Doledec et al. 1996) to investigate patch-scale relationships between the ecological and biological traits of the recorded species and the vegetation characteristics at each of our sites (Fig. 2). RLQ analysis is a three-table ordination technique that maximizes the covariance between species and the sites where they occur (table L) on the basis of the traits of the species (table Q) and the vegetation characteristics of the sites (table R). Species that occur in sites with similar vegetation characteristics are positioned close together in ordination space. Sites that contain species with similar traits are likewise placed close together.

RLQ analysis is constrained by separate ordinations of the R, L and Q tables (here represented by a Hill-Smith principal components analysis for mixed qualitative and quantitative data of tables $\mathrm{R}$ and $\mathrm{Q}$, and a correspondence analysis of table L). Thus, the total amount of variance explained by the RLQ analysis is limited by the variance explained by these separate ordinations. We therefore compared the results of the RLQ analysis with the separate ordinations to see how well the RLQ analysis explained the relationship between species traits and vegetation characteristics. We tested the significance of this relationship using a permutation test with 1000 permutations (Doledec et al. 1996). All analyses were conducted in the R statistical environment (R Development Core Team 2007), using the ade4 package (Dray and Dufour 2007).

Table 4 Seven vegetation characteristics were measured at each site and used in the RLQ analysis

\begin{tabular}{|c|c|c|}
\hline Vegetation characteristic & Category & Abbreviation \\
\hline \multirow[t]{7}{*}{ Dominant bark type of trees } & Gum & B:Gum \\
\hline & Box-gum & $\mathrm{B}: \mathrm{BxGm}$ \\
\hline & Box & B:Box \\
\hline & Stringybark & B:Stgy \\
\hline & Casuarina & $\mathrm{B}:$ Csa \\
\hline & Pine & B:Pine \\
\hline & Absent & B:Tless \\
\hline Stem density & $\begin{array}{l}\text { Approximate number of trees in each site; range }=[0,120] \text {, } \\
\text { mean }=49.8\end{array}$ & Stems \\
\hline \multirow[t]{2}{*}{ Tree hollows } & Present & Holl:Y \\
\hline & Absent & Holl:N \\
\hline \multirow[t]{2}{*}{ Eucalypt regeneration } & Present & Regen:Y \\
\hline & Absent & Regen:N \\
\hline Total shrub cover & $\begin{array}{l}\% \text { cover of shrubs, sum of small and large shrub height } \\
\text { layers; range }=[0,105], \text { mean }=26.1\end{array}$ & Shrubs \\
\hline \multirow{2}{*}{$\begin{array}{l}\text { Presence of blackberry (Rubus } \\
\text { fruticosus aggregate) }\end{array}$} & Present & Berry:Y \\
\hline & Absent & Berry:N \\
\hline Grass cover & $\%$ cover of grass; range $=[0,95]$, mean $=59.1$ & Grass \\
\hline
\end{tabular}


Fig. 2 Conceptual diagram of RLQ analysis, modified from Doledec et al. (1996). RLQ analysis links species traits to vegetation characteristics by the simultaneous ordination of a table of environmental conditions (R), a table of species presence/ absence (L), and a table of species traits (Q)

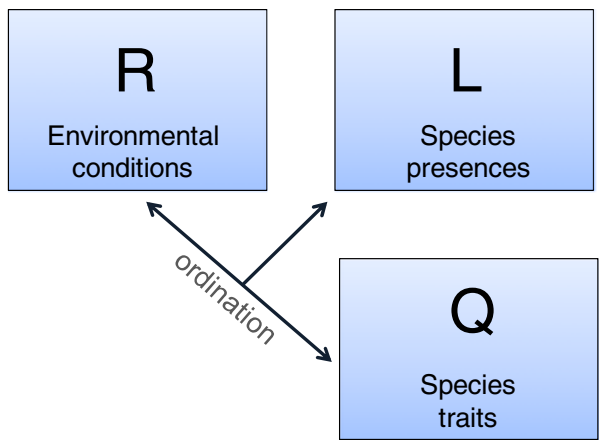

\section{Results}

Future development zone

The Molonglo Valley development zone (the area where development is planned) was located in the southeast of the study area and covered an area of 2062 ha, nearly one-third of total land in the study area (Fig. 1c, Table 1). Due to the spatial configuration of vegetation classes within the study area, the development zone did not include equal coverage of each vegetation class. More than $50 \%$ of the total river corridor in the study area fell within the development zone. Within the river corridor, $92 \%$ of treeless areas and $42 \%$ of treed areas were designated for development. Similarly, more than half of the plantation treed vegetation class fell within the development zone. In comparison, the development zone included $18 \%$ of the total treed and treeless rural land present in the Molonglo Valley.

\section{Relationship between species traits and vegetation characteristics}

We recorded 87 species of birds (Table 2). This represented $94 \%$ of species recorded at least five times in the study region during spring in the ten years preceding our study (Canberra Ornithologists Group, personal communication). Of the bird species, there were 53 woodland species, 20 generalists, eight grassland species, and six waterbirds.

The RLQ analyses revealed a significant relationship between the species traits and vegetation characteristics (permutation test $\mathrm{p}$-value $<0.001$ ), and the first two axes of the RLQ ordination together explained $92 \%$ of the total variance (Table 5). This represented $59 \%$ and $49 \%$ of the correlation expressed along the first and second axis in the correspondence analysis, $89 \%$ and $85 \%$ of the correlation expressed in the principal components analysis of the species traits, and $99 \%$ and $92 \%$ of the correlation expressed in the principal components analysis of the vegetation characteristics.

The first RLQ axis represented a gradient from sites with no or low shrub cover (mainly in the rural treed vegetation class) to sites with high shrub cover (riparian treed) (Fig. 3a and b). Rural treed sites were characterized by high grass cover, the presence of tree hollows and eucalypt regeneration, and gum and box-gum bark (Fig. 3a and b). Species traits associated with these vegetation characteristics included opportunistic nesters and hollow nesters, aerial insectivores, granivores, and carnivores, as well as larger-bodied (>50 g) species (Fig. 3c). Riparian treed sites were characterized by high shrub cover, casuarina bark and the presence of blackberry (Fig. 3a and b). These vegetation characteristics were associated with shrub insectivores, nectar and fruit and aquatic foragers, understory nesters, and very small-bodied species (Fig. 3c). 
Table 5 Results of RLQ analysis of the vegetation characteristics at each site (R), the species present (L), and their life-history traits (Q)

\begin{tabular}{llll}
\hline & & Axis 1 (\%) & Axis 2 (\%) \\
\hline Separate ordinations & R (Hill-Smith PCA) & $3.11(25.88)$ & $2.18(18.20)$ \\
& L (CA) & $0.52(9.08)$ & $0.41(7.20)$ \\
RLQ analysis & Q (Hill-Smith PCA) & $2.15(14.35)$ & $1.88(12.52)$ \\
& RLQ axis eigenvalues & $1.07(73.89)$ & $0.26(18.10)$ \\
& Covariance & 1.03 & 0.51 \\
& Correlation: L & $0.43(59.10)$ & $0.31(48.51)$ \\
& Projected variance: R & $3.08(99.40)$ & $4.85(91.75)$ \\
& Projected variance: Q & $1.91(88.53)$ & $3.43(85.19)$ \\
\hline
\end{tabular}

Separate ordinations: eigenvalues (and percent variance explained) for the first two axes from the ordinations of the R (Hill-Smith principal components analysis), L (correspondence analysis) and Q (Hill-Smith principal components analysis) tables. RLQ analysis: eigenvalues (and percent variance explained), covariance and correlation (and percent variance) with the correspondence analysis of the $\mathrm{L}$ matrix, and projected variance (and percent variance) with the $\mathrm{R}$ and $\mathrm{Q}$ matrices.

The second RLQ axis represented a tree cover gradient (Fig. 3a and b). Rural and riparian treed sites were characterized by a high number of tree stems, and stringybark and box bark. These characteristics were associated with arboreal insectivores and arboreal nesters (Fig. 3c). Rural treeless sites had no or low shrub cover and high grass cover, compared with the more shrubby riparian treeless sites (Fig. 3a and b). Both treeless vegetation classes were associated with ground foraging and nesting birds, and small-bodied species (Fig. 3c). Plantation treed sites grouped with the treeless sites, and were characterized by high shrub cover, pine bark and the presence of blackberry (Fig. 3a and b). There were no species traits strongly associated with this vegetation class (Fig. 3c).

The species habitat-association groups were related to the vegetation characteristics and species traits (Fig. 3d). Woodland species were present at sites ranging along the shrub gradient of the first axis, but were generally not found in treeless sites. In contrast, generalists were associated with sites with low shrub cover, but had no relationship with tree cover. Grassland species did not show a strong relationship with either the vegetation characteristics or vegetation classes. Waterbirds were associated with riparian sites.

\section{Discussion}

We investigated the bird community of a mixed-use landscape prior to urban development using RLQ analysis to relate bird species traits to patch-scale vegetation characteristics. We have shown how understanding the relationship between species traits and vegetation characteristics may improve understanding of bird community responses to urbanization and strengthen conservation in urban areas, despite some limitations to the application of the RLQ analysis method.

\section{Relationships between species traits and vegetation characteristics}

Community composition was influenced by landscape vegetation attributes, and species traits were clearly and directly related to vegetation characteristics. Many of the relationships 


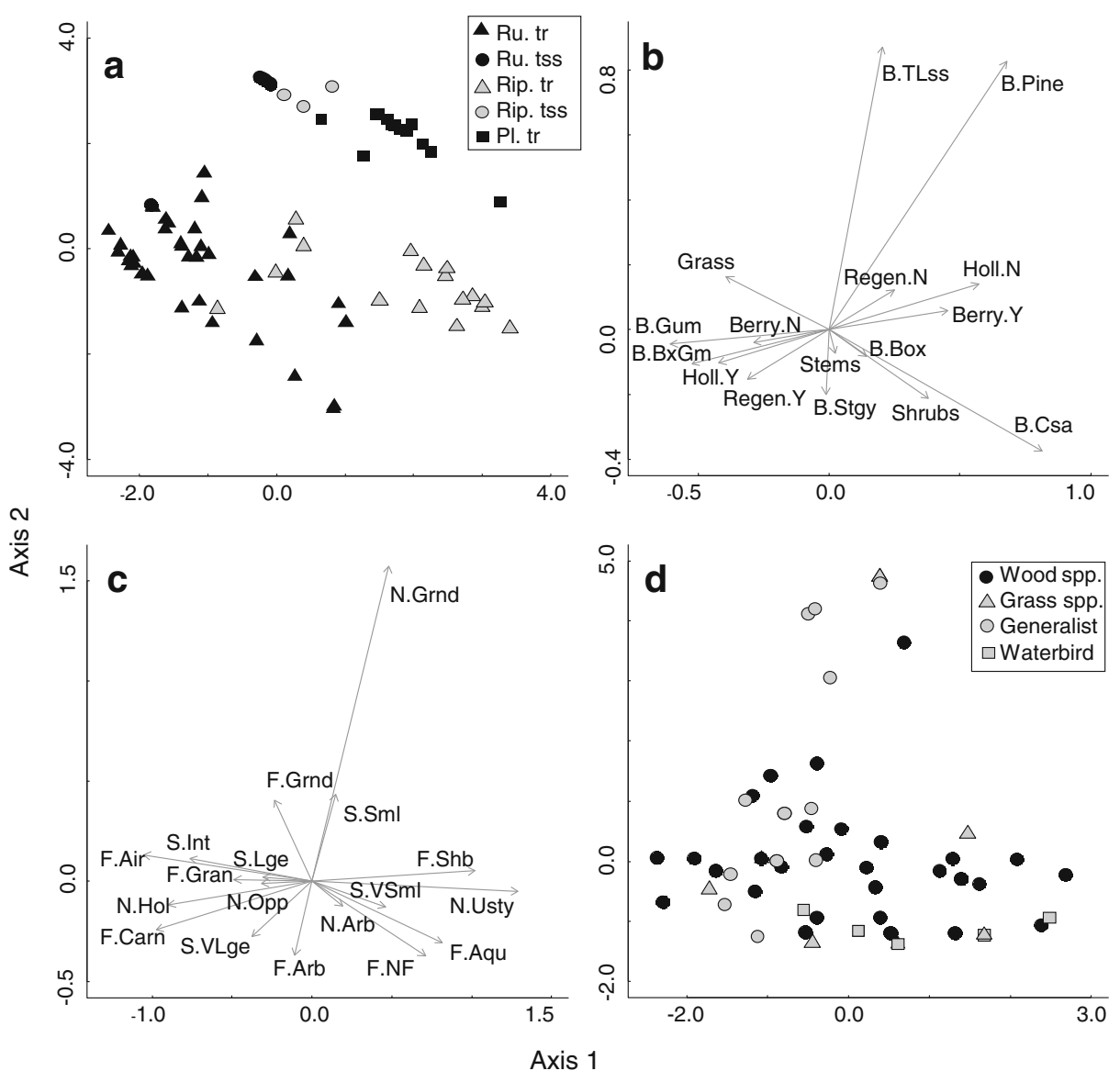

Fig. 3 RLQ scores along the first two axes: for (a) sampling sites grouped by vegetation class (abbreviations given in Table 1); (b) vegetation characteristics (abbreviations given in Table 3); (c) species traits (abbreviations given in Table 2); and (d) bird species grouped by habitat-association. Similar positions of sites, vegetation characteristics, species traits and species relative to the origin in the four plots indicate close associations. Positions of vegetation characteristics and species traits relative to the origin indicate relative contributions to the RLQ axes (plots $\mathbf{b}$ and $\mathbf{c}$ )

identified by RLQ analysis were expected. Intuitive examples included: (1) the association of arboreal nesters and foragers with high numbers of trees, and the converse relationship between ground nesters and treeless land; (2) the occurrence of shrub insectivores and understory nesters where shrub cover was high; and (3) the relationship between aerial insectivores and more open grassy conditions. Individual bird species are known to respond to vegetation characteristics (MacArthur 1964; McElhinny et al. 2006) and land-use history (Glennon and Porter 2005; Gustavsson et al. 2007), and our findings confirm that these responses are a function of their ecological and biological traits.

One implication of our results is that disturbances to particular vegetation characteristics are likely to affect particular species with traits related to those vegetation characteristics. For example, planned tree clearing for development is likely to affect 39 (45\%) of our 
recorded species that nest and/or forage arboreally. These species may not persist in a landscape with fewer trees or may face increased inter-specific competition for nest and food resources, possibly leading to local population declines or local extinction (Tilman et al. 1994; MacHunter et al. 2006; Huste and Boulinier 2007). For example, the loss of patches of hollow-bearing trees may negatively affect hollow-nesting parrots, such as the nationally threatened superb parrot, Polytelis swainsonii (EPBC Act 1999).

Similarly, riparian and treeless areas had a high proportion of land within the development zone, relative to their total land cover within the study area, and so birds with traits associated with these vegetation classes are likely to be disproportionately affected. These include species that forage and nest on the ground and in the understory strata, and smallerbodied $(<50 \mathrm{~g})$ species, as well as waterbirds and woodland species. Small-bodied ground and understory species have been identified as declining or sensitive to disturbance in some studies in southeast Australia (Antos and Bennett 2005; Antos and Bennett 2006; Olsen et al. 2006; Barrett et al. 2008). Thus, it is a matter of conservation concern that it is this group of species that may also be under threat due to habitat modification caused by urban development.

Depending on the nature of urban development, it may, in the longer term, create a heterogeneous environment able to support a variety of bird species, but these are likely to represent a new bird community (Emlen 1974; Garden et al. 2006; Ortega-Alvarez and MacGregor-Fors 2009). It is improbable that future urbanization within our study area will result in suitable habitat for many of the small ground and understory species that form part of the current bird community. This is because current development trends are for smaller house blocks with limited garden space forming part of a more compact urban design (MacKenzie and Barnett 2006). Similarly, public open spaces are typically characterized by a low density of small eucalypt or exotic trees, with very little understory cover. Birds associated with these vegetation characteristics include larger-bodied, generalist species (French et al. 2005; Garden et al. 2006; Parsons et al. 2006; Catterall et al. 2010), and it is likely that these species will dominate the future urban bird community, as has been found in older suburbs in Canberra (K. Ikin, unpublished manuscript).

Based on the relationships between species traits and vegetation characteristics, four plausible high-priority actions to maintain the current bird community within the Molonglo Valley development zone would be: (1) river restoration; (2) maintenance of a shrub understory (possibly around stands of remnant trees); (3) preservation of grassland areas (e.g. within public open spaces); and (4) promotion of vegetation heterogeneity across the urban landscape. These actions may help sustain the high diversity of woodland and grassland species in the Molonglo Valley, particularly those directly at risk from development. How these actions are carried out, for example with respect to the size and configuration of grassland areas, should be determined prior to development and with the aim of increasing habitat connectivity in the landscape (Gordon et al. 2009).

It is important to note that our focus on direct patch-scale relationships between species traits and vegetation characteristics may have underestimated the impacts of urbanization on the bird community. In addition to patch-scale impacts due to vegetation modification, future urban development may have larger-scale impacts across the landscape (Clergeau et al. 2001; Dunford and Freemark 2005). Many species use a variety of vegetation characteristics within a landscape, and at different spatial scales (Donnelly and Marzluff 2004; Haslem and Bennett 2008a,b), and landscape context can influence the presence of species within vegetation patches. For example, many bird species are intolerant of urbanization, and may avoid vegetation that is within or adjacent to urban areas, despite being otherwise suitable habitat (Blair 1996; Crooks et al. 2004; Catterall 2009; Huste and Boulinier 2011). 
Implications for urban planning

Determining the relationship between species traits and vegetation characteristics could be useful to identify potentially critical habitat and species at risk from development (Rossi and Kuitunen 1996; Mandelik et al. 2005). RLQ analysis has potential, therefore, to be a useful tool for planners in a number of ways.

First, analyses conducted early in the urban planning process could be used to plan development away from important areas or to allocate proposed land uses in an ecologically sensitive way. Ecological considerations may often only be addressed effectively in early stages of urban planning. Giving them high priority in initial project design may avoid expensive and time-consuming damage mitigation at later stages (Treweek 1996).

Second, RLQ analysis could make a useful contribution to mitigation recommendations because it allows predictions of which types of species characterized by particular life history traits may be affected by proposed urban development actions. In turn, this understanding could be used to proactively address negative effects of urbanization, e.g. through altering project design, or restoring or revegetating particular vegetation types. For example, urban development in the Molonglo Valley may negatively affect understory nesters and foragers, and so we would recommend planting shrubs within urban open space to minimize habitat loss for these species. RLQ analysis can complement other scientific approaches that inform how these actions should be performed, such as which species of shrubs should be planted and in which configuration, or when species monitoring should occur.

Third, relating species traits to environmental conditions may allow us to distinguish between high and low priority actions. For example, in the Molonglo Valley, the rural treed vegetation class may be minimally affected in proportion to the total land cover of this class in the landscape, and thus mitigation efforts for rural treed areas might have a lower priority in comparison to other classes. We note, however, that rural treed vegetation was associated with a critically endangered ecological community (White Box-Yellow Box-Blakely's Red Gum Grassy Woodland and Derived Native Grassland, EPBC Act 1999), as well as disturbance-sensitive species traits, for example hollow nesting (Gibbons and Lindenmayer 2002; Manning et al. 2004). When prioritizing actions, therefore, consideration of broader legal protection and larger scale ecological roles is also needed.

\section{Conclusions}

A significant challenge in urban planning is to undertake proactive conservation action, and mitigate negative effects of urbanization on animal communities before development begins. In our case study of a bird community in a mixed-use landscape, we have demonstrated that relating bird species traits to vegetation characteristics may assist greatly with this challenge by identifying which habitat-association groups, species guilds, and vegetation characteristics are likely to be most affected by the future urbanization of the landscape. Our study outcomes have broad relevance for animal conservation and urban planning elsewhere in the world where urbanization is rapidly occurring, such as the Americas, Asia and Europe (McDonnell and Hahs 2008; Ignatieva 2010).

Acknowledgments We thank Steve Holliday for his help with field work. Philip Barton and Kylie Mulligan provided constructive comments on the manuscript. Discussions with Penny Olsen, Murray Evans and Ross Cunningham improved the experimental design. We thank Jeff Wood and Jan Hanspach for their statistical advice, and staff from ACT Conservation, Planning and Research, the ACT Planning and Land Authority, and the Land Development Agency for providing vegetation and development maps. K.I. was the recipient of the 
Molonglo Valley PhD independent research scholarship, jointly funded by the Fenner School of Environment and Society (The Australian National University) and Conservation, Planning and Research (ACT Government). Ethics approval was obtained before conducting out this work (C.RE.53.08).

\section{References}

ACTPLA (2006) Molonglo Valley structure plan. ACT Planning and Land Authority, ACT Government

Antos MJ, Bennett AF (2005) How important are different types of temperate woodlands for ground-foraging birds? Wildl Res 32:557

Antos MJ, Bennett AF (2006) Foraging ecology of ground-feeding woodland birds in temperate woodlands of southern Australia. Emu 106:29-40

Barbaro L, van Halder I (2009) Linking bird, carabid beetle and butterfly life-history traits to habitat fragmentation in mosaic landscapes. Ecography 32:321-333

Barrett G, Silcocks A, Cunningham R, Oliver DL, Weston M, Baker J (2007) Comparison of atlas data to determine the conservation status of bird species in New South Wales, with an emphasis on woodlanddependant species. Aust Zool 34(1):37-77

Barrett G, Freudenberger D, Drew A, Stol J, Nicholls AO, Cawsey EM (2008) Colonisation of native tree and shrub plantings by woodland birds in an agricultural landscape. Wildl Res 35:19-32

Bernhardt-Romermann M, Romermann C, Nuske R, Parth A, Klotz S, Schmidt W, Stadler J (2008) On the identification of the most suitable traits for plant functional trait analyses. Oikos 117(10):1533-1541

Blair RB (1996) Land use and avian species diversity along an urban gradient. Ecol Appl 6(2):506-519

Brind'Amour A, Boisclair D, Dray S, Legendre P (2011) Relationship between species feeding traits and environmental conditions in fish communities: a three-matrix approach. Ecol Appl 21(2):363-377

Catterall CP (2009) Responses of faunal assemblages to urbanisation: global research paradigms and an avian case study. In: McDonnell MJ, Hahs AK, Breuste JH (eds) Ecology of cities and towns: a comparative approach. Cambridge University Press, Cambridge, pp 129-155

Catterall CP, Cousin JA, Piper S, Johnson G (2010) Long-term dynamics of bird diversity in forest and suburb: decay, turnover or homogenization? Divers Distrib 16(4):559-570

Christidis L, Boles W (2008) Systematics and taxonomy of Australian birds. CSIRO Publishing, Collingwood

Cleary DF, Boyle TJ, Setyawati T, Anggrawni CD, Van Loon EE, Menken SB (2007) Bird species and traits associated with logged and unlogged forest in Borneo. Ecol Appl 17(4):1184-1197

Cleary DF, Genner MJ, Koh LP, Boyle TJ, Setyawati T, de Jong R, Menken SB (2009) Butterfly species and traits associated with selectively logged forest in Borneo. Basic Appl Ecol 10:237-245

Clergeau P, Jokimaki J, Savard J-PL (2001) Are urban bird communities influenced by the bird diversity of adjacent landscapes? J Appl Ecol 38:1122-1134

Crooks KR, Suarez AV, Bolger DT (2004) Avian assemblages along a gradient of urbanization in a highly fragmented landscape. Biol Conserv 115:451-462

deMars CA, Rosenberg DK, Fontaine JB (2010) Multi-scale factors affecting bird use of isolated remnant trees in agro-ecosystems. Biol Conserv 143:1485-1492

de Voogd NJ, Cleary DF (2007) Relating species traits to environmental variables in Indonesian coral reef sponge assemblages. Mar Freshw Res 58:240-249

Doledec S, Chessel D, Ter Braak C, Champely S (1996) Matching species traits to environmental variables: a new three-table ordination method. Environ Ecol Stat 3:143-166

Donnelly R, Marzluff JM (2004) Importance of reserve size and landscape context to urban bird conservation. Conserv Biol 18(3):733-745

Dray S, Dufour A-B (2007) The ade4 package: implementing the duality diagram for ecologists. J Stat Softw 22(4):1-20

Duchamp JE, Swihart RK (2008) Shifts in bat community structure related to evolved traits and features of human-altered landscapes. Landsc Ecol 23:849-860

Dunford W, Freemark K (2005) Matrix matters: effects of surrounding land uses on forest birds near Ottawa, Canada. Landsc Ecol 20(5):497-511

Emlen JT (1974) An urban bird community in Tucson, Arizona: derivation, structure, regulation. Condor 76:184-197

Environment Protection and Biodiversity Conservation Act (1999) In: Cth

Foley JA, DeFries R, Asner GP, Barford C, Bonan G, Carpenter SR, Chapin FS, Coe MT, Daily GC, Gibbs HK, Helkowski JH, Holloway T, Howard EA, Kucharik CJ, Monfreda C, Patz JA, Prentice C, Ramankutty N, Snyder PK (2005) Global consequences of land use. Science 309:507-574 
Ford HA, Barrett GW, Saunders DA, Recher HF (2001) Why have birds in the woodlands of southern Australia declined? Biol Conserv 97:71-88

French K, Major RE, Hely K (2005) Use of native and exotic garden plants by suburban nectarivorous birds. Biol Conserv 121:545-559

Garden J, McAlpine C, Peterson A, Jones D, Possingham HP (2006) Review of the ecology of Australian urban fauna: a focus on spatially explicit processes. Austral Ecol 31:126-148

Gibbons P, Lindenmayer DB (2002) Tree hollows and wildlife conservation in Australia. CSIRO Publishing, Collingwood

Glennon MJ, Porter WF (2005) Effects of land use management on biotic integrity: an investigation of bird communities. Biol Conserv 126:499-511

Gordon A, Simondson D, White M, Moilanen A, Bekessy SA (2009) Integrating conservation planning and landuse planning in urban landscapes. Landsc Urban Plan 91:183-194

Gustavsson E, Lennartsson T, Emanuelsson M (2007) Land use more than 2008 years ago explains current grassland plant diversity in a Swedish agricultural landscape. Biol Conserv 138:47-59

HANZAB (1990-2007) Handbook of Australian, New Zealand and Antarctic birds, volumes 1-7, Oxford University Press, Melbourne

Haslem A, Bennett AF (2008a) Birds in agricultural mosaics: the influence of landscape pattern and countryside heterogeneity. Ecol Appl 18(1):185-196

Haslem A, Bennett AF (2008b) Countryside elements and the conservation of birds in agricultural environments. Agric Ecosyst Environ 125:191-203

Hausner VH, Yoccoz NG, Ims RA (2003) Selecting indicator traits for monitoring land use impacts: birds in northern coastal birch forests. Ecol Appl 13(4):999-1012

Heikkinen RK, Luoto M, Virkkala R, Rainio K (2004) Effects of habitat cover, landscape strucure and spatial variables on the abundance of birds in an agricultural-forest mosaic. J Appl Ecol 41:824-835

Hirzel AH, Le Lay G (2008) Habitat suitability modelling and niche theory. J Appl Ecol 45(5):1372-1381

Huste A, Boulinier T (2007) Determinants of local extinction and turnover rates in urban bird communities. Ecol Appl 17(1):168-180

Huste A, Boulinier T (2011) Determinants of bird community composition on patches in the suburbs of Paris, France. Biol Conserv 144:243-252

Ignatieva M (2010) Design and future of urban biodiversity. In: Muller N, Werner P, Kelcey JG (eds) Urban biodiversity and design. Blackwell Publishing, Oxford

Kennedy CM, Marra PP, Fagan WF, Neel MC (2010) Landscape matrix and species traits mediate responses of Neotropical resident birds to forest fragmentation in Jamaica. Ecol Monogr 80(4):651-669

Lacourse T (2009) Environmental change controls postglacial forest dynamics through interspecific differences in life-history traits. Ecology 90(8):2149-2160

LDA (2010) Molonglo Valley frequently asked questions, last updated 11 June 2010, Land Development Agency

Le Viol I, Julliard R, Kerbiriou C, de Redon L, Carnino N, Machon N, Porcher E (2008) Plant and spider communities benefit differently from the presence of planted hedgerows in highway verges. Biol Conserv 141:1581-1590

Lindenmayer DB, Cunningham RB (2011) Longitudinal patterns in bird reporting rates in a threatened ecosystem: is change regionally consistent? Biol Conserv 144:430-440

Lizée M-H, Bonardo R, Mauffrey J-F, Bertaudiere-Montes V, Tatoni T, Deschamps-Cottin M (2011) Relative importance of habitat and landscape scales on butterfly communities in urbanizing areas. C R Biol 334:74-84

Loyn R, Kennedy S (2009) Designing old forest for the future: old trees as habitat for birds in forests of Mountain Ash Eucalyptus regnans. For Ecol Manage 258:504-515

MacArthur RH (1964) Environmental factors affecting bird species diversity. Am Nat 98(903):387-397

MacHunter J, Wright W, Loyn R, Rayment P (2006) Bird declines over 22 years in forest remnants in southeastern Australia: evidence of faunal relaxation? Can J For Res 36:2756-2768

MacKenzie A, Barnett G (2006) The bush capital - a complex urbanising landscape. The Landscape Architect, IFLA Conference Papers

Mac Nally R (1994) Habitat-specific guild structure of forest birds in south-eastern Australia: a regional scale perspective. J Anim Ecol 63:988-1001

Mandelik Y, Dayan T, Feitelson E (2005) Planning for biodiversity: the role of ecological impact assessment. Conserv Biol 19(4):1254-1261

Manning AD, Lindenmayer DB, Barry S (2004) The conservation implications of bird reproduction in the agricultural 'matrix': a case study of the vulnerable superb parrot of south-eastern Australia. Biol Conserv 120:363-374

Manning A, Wood J, Cunningham R, McIntyre S, Shorthouse D, Gordon I, Lindenmayer D (2011) Integrating research and restoration: the establishment of a long-term woodland experiment in south-eastern Australia. Aust Zool 35:633-648 
McDonald RI (2008) Global urbanization: can ecologists identify a sustainable way forward? Front Ecol Environ 6(2):99-104

McDonnell MJ, Hahs AK (2008) The use of gradient analysis studies in advancing our understanding of the ecology of urbanizing landscapes: current status and future directions. Landsc Ecol 23:1143-1155

McElhinny C, Gibbons P, Brack C, Bauhus J (2006) Fauna-habitat relationships: a basis for identifying key stand structural attributes in temperate Australian eucalypt forests and woodlands. Pac Conserv Biol 12:89-110

Montague-Drake R, Lindenmayer DB, Cunningham R (2009) Factors effecting site occupancy by woodland bird species of conservation concern. Biol Conserv 142(12):2896-2903

O'Connell TJ, Jackson LE, Brooks RP (2000) Bird guilds as indicators of ecological condition in the central Appalachians. Ecol Appl 10(6):1706-1721

Olsen P, Silcocks A, Weston M, Tzaros C (2006) Birds of woodlands and grasslands. In: Australia: State of the Environment Report, Department of the Environment and Heritage, Canberra

Ortega-Alvarez R, MacGregor-Fors I (2009) Living in the big city: effects of urban land-use on bird community structure, diversity and composition. Landsc Urban Plan 90:189-195

Parsons H, Major RE, French K (2006) Species interactions and habitat associations of birds inhabiting urban areas of Sydney, Australia. Austral Ecol 31:217-227

Rachello-Dolmen, Cleary DF (2007) Relating coral species traits to environmental conditions in the Jakarta Bay/Pulau Seribu reef system, Indonesia. Estuar Coast Shelf Sci 73:816-826

R Development Core Team (2007) R: a language and environment for statistical computing. R Foundation for Statistical Computing

Reid JRW (1999) Threatened and declining birds in the New South Wales sheep-wheat belt: I. diagnosis, characteristics and management. In: Consultancy report to the NSW National Parks and Wildlife Service, CSIRO Wildlife and Ecology, Canberra

Ribera I, Doledec S, Downie IS, Foster GN (2001) Effect of land disturbance and stress on species traits of ground beetle assemblages. Ecology 82(4):1112-1129

Rossi E, Kuitunen M (1996) Ranking of habitats for the assessment of ecological impact in land use planning. Biol Conserv 77(2-3):227-234

Seymour CL, Dean WRJ (2010) The influence of changes in habitat structure on the species composition of bird assemblages in the southern Kalahari. Austral Ecol 35:581-592

Silcocks A, Tzaros C, Weston M, Olsen P (2005) An interim guild classification for woodland and grassland birds in Australia, Birds Australia Supplementary Report to State of the Environment Report 2006, Carlton

Soderstrom B, Part T, Linnarsson E (2001) Grazing effects on between-year variation of farmland bird communities. Ecol Appl 11(4):1141-1150

Soule ME (1991) Land use planning and wildlife maintenance: guidelines for conserving wildlife in an urban landscape. J Am Plann Assoc 57(3):313-323

Stagoll K, Manning AD, Knight E, Fischer J, Lindenmayer DB (2010) Using bird-habitat relationships to inform urban planning. Landsc Urban Plan 98(1):13-25

Sutherland WJ, Newton I, Green RE (2004) Bird ecology and conservation: a handbook of techniques. In: Sutherland WJ (ed) Techiques in ecology and conservation series. Oxford University Press, Oxford

Threlfall C, Law B, Penman T, Banks PB (2011) Ecological processes in urban landscapes: mechanisms influencing the distribution and activity of insectivorous bats. Ecography 33:1-13

Tilman D, May RM, Lehman CL, Nowak MA (1994) Habitat destruction and the extinction debt. Nature 371:65-66

Treweek J (1996) Ecology and environmental impact assessment. J Appl Ecol 33(2):191-199

Webb CT, Hoeting JA, Ames GM, Pyne MI, Poff NL (2010) A structured and dynamic framework to advance traits-based theory and prediction in ecology. Ecol Lett 13(3):267-283

Williams NM, Crone EE, Roulston TAH, Minckley RL, Packer L, Potts SG (2010) Ecological and life-history traits predict bee species responses to environmental disturbances. Biol Conserv 143(10):2280-2291 